\title{
Consideraciones sobre el "origen alemán de la Comunidad Terapéutica”.
}

El número 105 de la Revista, en "Originales Breves", incluye el artículo de Fernando Pérez del Río titulado "Origen alemán de la Comunidad Terapéutica", cuya lectura me ha movido a enviarles algunas observaciones y precisiones históricas y conceptuales.

1.- La idea de Comunidad Terapéutica está indisolublemente vinculada a Maxwell Jones y al Henderson Hospital, pero su "descubrimiento" por dicho autor es unos años anterior, en la Escuela Mill Hill, cuando tuvo a su cargo una unidad de cien camas ocupadas por personal de las fuerzas armadas. Dice el propio Jones... "En 1941... mis colegas y yo nos dimos cuenta de que los pacientes aprendian mucho mas sobre su condición si participaban plenamente en una interacción y discusión con nosotros..." "Para fines de la guerra estábamos convencidos de que las personas... juntas en un hospital ya sean pacientes o del cuerpo médico, obtenían gran beneficio del examen en reuniones comunitarias cotidianas sobre que estaban haciendo y porque lo estaban haciendo..." Recupera el valor de la palabra del interno cuya negación es el elemento esencial del manicomio y de otras instituciones totales, a la vez que descubre el valor de la cooperación y la mutua ayuda, que los enfermos mentales hospitalizados tienen su mejor apoyo en otros pacientes, y que los problemas colectivos exigen respuestas colectivas... La trayectoria vital y profesional posterior de M. Jones saca del ámbito institucional psiquiátrico sus conceptos y experiencias, trasladándolas a escuelas y prisiones norteamericanas, "más allá de la Comunidad Terapéuti$c a$ ". En el trasfondo de las experiencias iniciales están las reflexiones y trabajos del grupo de Northfield.

2.- Algunos sitúan en Estados Unidos de América el origen de la Comunidad Terapéutica, en los años 20, por la misma época que Simmel. Nos referimos a Harry Stack Sullivan, en Baltimore. De este país son las aportaciones de la microsociología (Belknap, Goffman) y de la antropología social (Caudill), así como formas de colaboración fecunda entre psiquiatras y psicólogos (Stanton y Schwartz). De los tres autores últimamente citados es el señalamiento en momentos y contextos diferentes de la importancia de las otras 23 horas, (frente a la hora de supuesta terapia individual), la trascendencia del apoyo de los demás pacientes, de los trabajadores no cualificados, que ya había puesto de manifiesto 
M. Jones: "La solución que ofrece la Comunidad Terapéutica es la libre discusión de la totalidad de las circunstancias por todos los comprometidos en ella, sin distinción alguna de títulos académicos, administrativos o jerárquicos...”.

3.- En otros países hay matices diferenciales. En Italia, Basaglia, desde la primera mitad de los 60 defiende la utilización de la Comunidad Terapéutica como instrumento técnico en el proceso de desmantelamiento del manicomio, sin perder de vista el riesgo de congelación del proceso y nacimiento de un nuevo instrumento de control científico de la desviación. En Francia, además de la experiencia analizada por Levy, y otras, la psicoterapia institucional coincide con muchos elementos de la Comunidad Terapéutica en un lenguaje psicoanalítico, vinculación que ya estaba presente en alguno de los miembros del grupo de Northfield.

4.- En España una de las primeras experiencias vincula Comunidad Terapéutica y Psicoanálisis (1968, Gallego y Campoy) debiendo ser conocidas otras publicaciones posteriores sustentadas en prácticas asistenciales concretas, y no en mera recopilación bibliográfica (Ignacio Bellido, 1971 y 1972, Castillón y otros 1978, Montoya Rico, capítulos 47 y 49 del Manual de González de Rivera y otros, editado por Karpós en 1980).

Tras aquellas experiencias pioneras, los desarrollos posteriores en nuestro país pueden calificarse como deriva o perversión tecnoburocrática cuyas máximas expresiones son, por una parte, la definición de Comunidad Terapéutica en las Bases para una Política de Salud Mental del P.S.O.E., en 1982, como un centro psicoterapéutico caro, dirigido a neuróticos graves y, por otra, uno de los centros experimentales de la Reforma Andaluza, en 1990, La Comunidad Terapéutica de un hospital sevillano que contaba con 5 pacientes para cuya atención trabajaban 42 personas, entre psicólogos, psiquiatras, monitores y asistentes sociales algo calificado de vergonzoso a la vez que esperpéntico.

5.- En la revisión histórica Fernando Pérez del Río se queda en Alemania en los años 20, y se ha citado a Sullivan, por la misma época. Pero existen precedentes anteriores, incluso muy anteriores. En la primera mitad del siglo XIX, en Gran Bretaña, John Conolly, en el manicomio de Hanwell elimina la restricción física a los pacientes (como Hill, por la misma época, en el Lincoln Asylum), inicia reuniones conjuntas de enfermos y personal y sitúa su práctica en un contexto asistencial mas amplio, que incluye asistencia extrahospitalaria, atención domiciliaria y colaboración con los médicos de cabecera.

Muchos años antes, y según cronistas (Benjamín de Tudela), historiadores (Evilija) u otros estudiosos (Jervis, Schittar) desde antes del año 1000 y hasta el siglo XV los maristanes árabes basaban la atención a los alienados en la libertad de movimientos, los juegos y el trabajo, así como en la utilización de la palabra, la ayuda económica para las altas, y asistencia en la comunidad, para lo que 
CARTAS AL EDITOR

contaban con recursos incluidos medios para desplazarse, (camellos) para transportar el instrumental, los medicamentos, los médicos y los enfermeros.... De la comunidad entendida como grupo de personas que conviven en una institución a la comunidad entendida como colectividad exterior. De la Comunidad Terapéutica a la Psiquiatría Comunitaria o Salud Mental Poblacional, es una articulación, como vemos, con varios siglos de historia.

Onésimo González Álvarez. 